\title{
Identificación y Caracterización Molecular de Aislados de Burkholderia glumae, Agente Causante del Añublo Bacterial en el Cultivo de Arroz
}

\author{
Fabián Galvis* y Marlen Carrillo \\ Grupo de Investigación Biogen, Universidad de Santander, Cúcuta, Norte de Santander-Colombia \\ (e-mail: fgs999@hotmail.com) \\ * autor a quien debe ser dirigida la correspondencia
}

Recibido Jul. 25, 2014; Aceptado Oct. 13, 2014; Versión final recibida Dic. 13, 2014

\begin{abstract}
Resumen
El objetivo de este trabajo fue implementar la identificación especifica de Burkholderia glumae por PCR convencional; y conocer sus características genéticas, a partir de plantas de arroz con evidencia de pudrición. Burkholderia glumae es el agente causal del añublo bacterial de la panícula del arroz, con una alta incidencia ocasionando considerables pérdidas en la producción de los cultivos en Colombia. Debido a que su identificación es difícil, se requiere de un sistema de evaluación que permita determinar de manera rápida y precisa este patógeno. Se obtuvo 64 aislados, de los cuales 41 fueron identificados por Reacción en Cadena de la Polimerasa (PCR) como Burkholderia glumae. La caracterización molecular con los marcadores MB1 y BOX-PCR mostraron variabilidad genética en la mayoría de los aislados, pero permitieron el agrupamiento de acuerdo a su origen geográfico. La gran diversidad genética encontrada refleja el alto grado de variabilidad existente dentro de los individuos de esta especie.
\end{abstract}

Palabras clave: Burkholderia glumae, añublo bacterial, cultivo de arroz, PCR

\section{Identification and Characterization Molecular of Burkholderia glumae, Causal Agent of Bacterial Panicle Blight in Rice}

\begin{abstract}
The aim of this study was to identify and molecularly characterize isolates of Burkholderia glumae from rice plants with evidence of putrescence. Burkholderia glumae is the causal agent of bacterial blight of panicle rice, with a high incidence causing considerable losses in crop production in Colombia. Since its identification is difficult, it is important to implement an evaluation system to quickly and accurately identify this pathogen. Sixty four isolates were obtained, 41 of which were identified by polymerase chain reaction (PCR) as Burkholderia glumae. The molecular characterization with MB1 and BOX-PCR markers showed genetic variability in most isolates, but allowed the grouping according to its geographical origin. The high genetic diversity suggests a high degree of variability within individuals of this species.
\end{abstract}




\section{INTRODUCCIÓN}

El arroz (Oryza sativa) constituye el principal alimento de más de dos mil millones de personas, con un área sembrada de 147 millones de hectáreas (ha) y una producción mundial de 618 millones de toneladas; y se estima que para el año 2030 la demanda de arroz supere los 770 millones de toneladas (Cristo et al., 2010). En Colombia en el primer semestre de 2013, el área sembrada fue de 293.179 ha. En Norte de Santander se cultiva arroz en 9 de los 40 municipios que lo componen: Cúcuta, El Zulia, Tibú, San Cayetano, La Esperanza, Puerto Santander, Villa del Rosario, Los Patios y Santiago, agrupando un área de producción de 14.200 ha cultivadas por el sistema de riego (Cuevas, 2012). En Colombia las enfermedades por bacterias causan entre un 80 a $90 \%$ de pérdidas en la producción del cultivo del arroz. Burkholderia glumae es el agente principal del añublo bacterial de la panícula (ABP). Los síntomas del ABP presentes en el cultivo del arroz son: panículas erectas con pérdidas significativas en el rendimiento por el vaneamiento o reducción del peso del grano, decoloración del grano tomando un color pajizo, raquis verde, hoja bandera sana de un color verde intenso, esterilidad de las flores e inhibición en la germinación de la semilla (Nandakumar et al., 2009; Ham et al., 2011). En Colombia no existen reportes claros sobre las pérdidas generadas por $B$. glumae, ya que son difíciles de estimar a partir de los componentes de rendimiento, debido a la diversidad de factores, como variedad, clima, cantidad de inóculo y manejo del cultivo, que están presentes en el desarrollo de la enfermedad. (Flórez \& Uribe, 2011). Aunque es evidente que algunos componentes de rendimiento son afectados conforme aumenta el grado de la enfermedad, tales como el número de granos llenos y el peso de mil granos, los cuales combinados, pueden llegar a reducir en un $50 \%$ el rendimiento cuando se alcanzan los mayores niveles de la enfermedad (Diago et al., 2009).

Las estrategias para combatir el ABP se han enfocado en el establecimiento de técnicas moleculares para el diagnóstico específico y análisis de la enfermedad, complementadas con el manejo integral del cultivo, la determinación de variedades resistentes o tolerantes, y la elección adecuada de las épocas de siembra para disminuir la incidencia (Fedearroz, 2012). Entre las técnicas de diagnóstico molecular, la Reacción en Cadena de la Polimerasa (PCR) se ha estandarizado para la confirmación de la presencia de B. glumae en el cultivo del arroz (Onasanya et al., 2010). La caracterización molecular por rep-PCR se basa en la amplificación por PCR de secuencias de ADN intergénicas repetidas presentes en genomas de procariotas (Lupski y Weinstock, 1992; Rademaker et al., 2000). Estas secuencias se denominan rep y comprenden principalmente tres marcadores: REP (Repetitive Extragenic Palindromic Sequences), BOX (secuencias de la subunidad BOXA del elemento BOX de Streptococcus pneumoniae) y ERIC (Enterobacterial Repetitive Intergenic Concensus).

En Colombia B. glumae ha cobrado importancia como agente fitopatógeno del arroz, así como el hecho de que se desconocen factores relevantes de la biología de la relación planta-patógeno con las variedades colombianas, como la capacidad del patógeno de desarrollar la enfermedad a partir de semillas infectadas, lo cual puede ser fácilmente estudiado a través del análisis de diversos sistemas de infección y el conocimiento de sus características genéticas con sus relaciones ecológicas y de patogenicidad (Flórez \& Uribe, 2011). El presente trabajo se realizó con el fin de validar el diagnostico especifico de $B$. glumae mediante PCR convencional; y conocer las características genéticas de B. glumae, utilizando marcadores moleculares para precisar las relaciones filogenéticas, a partir de aislados de cultivos de arroz de dos diferentes zonas arroceras de Norte de Santander, Colombia.

\section{METODOLOGÍA}

\section{Material biológico}

Se utilizaron plantas de arroz con síntomas de vaneamiento y manchado de grano y tallo, provenientes de cultivos de los municipios de Cúcuta y El Zulia, Norte de Santander, Colombia. Como controles positivos se emplearon cepas de Burkholderia glumae y B. cepacia, facilitados por el Centro Internacional de Agricultura Tropical (CIAT).

\section{Análisis microbiológico de los controles positivos}

Para la reactivación y comprobación de pureza de las cepas control de Burkholderia glumae y $B$. cepacia, se cultivaron en medio JMV con incubación por 5 días con agitación constante $(150 \mathrm{rpm})$ a $30^{\circ} \mathrm{C}$. Se determinaron las características macroscópicas típicas: colonias grandes y blancas, con pigmentación amarilla en su centro y mucoides.

\section{Aislamiento microbiológico de las panículas de arroz}

Las panículas de cada planta de arroz se lavaron con agua destilada estéril y se cortaron en segmentos de $1 \mathrm{~cm}$ aproximadamente. La desinfección superficial se realizó lavando cada tejido por separado en agua 
destilada estéril, seguido de un lavado en buffer fosfato y agitación por 15 minutos, posteriormente se sumergió el tejido en alcohol al 70\% durante 1 minuto, seguido de un lavado en una solución de hipoclorito de sodio al $5 \%$ y Tween $80 \%$ con una agitación por 5 min; y finalmente, el tejido fue lavado cuatro veces en agua destilada estéril (Pérez et al., 2010). Después del proceso de desinfección, el tejido fue colocado en un matraz y macerado con ayuda de nitrógeno líquido hasta obtener una mezcla homogénea. Luego se sembraron en agua peptonada al $1 \%$ y se incubaron por 15 minutos. Se realizaron diluciones hasta $10^{-7}$ y de cada dilución se tomaron $0,1 \mathrm{ml}$ y se sembraron en medio selectivo JMV con incubación a $30^{\circ} \mathrm{C}$ por 5 días. Se determinaron características macroscópicas típicas: colonias grandes y blancas, con pigmentación amarilla en su centro y mucoides.

\section{Aislamiento del ADN}

Para la extracción del ADN de los aislados bacterianos se utilizó el kit UltraClean® Microbial DNA Isolation de la casa comercial MoBio. Para la obtención de ADN a partir de panículas de plantas de arroz se emplearon dos métodos: 1) El descrito por Lu et al., (2011): donde se maceran $200 \mathrm{mg}$ de tejido de panícula con ayuda de nitrógeno líquido, se adicionan $700 \mathrm{ml}$ de tampón de extracción $(2 \% \mathrm{CTAB}, 100 \mathrm{mM}$ Tris- $\mathrm{HCl}$, $20 \mathrm{mM}$ EDTA, $1.4 \mathrm{M} \mathrm{NaCl}, 0.2 \% \beta$-mercaptoethanol, pH 8) y se incuba por 30 minutos a $60^{\circ} \mathrm{C}$, se agregan $600 \mathrm{ml}$ de cloroformo:alcohol isoamílico (24:1) y se centrifuga por 20 minutos a $12.000 \mathrm{rpm}$ recuperándose la fase acuosa, luego se adicionan $1 \mathrm{ml}$ de etanol absoluto frio y se almacena por 20 minutos a $-20^{\circ} \mathrm{C}$ para precipitar el ADN, posteriormente se centrifugan por 10 minutos a $12.000 \mathrm{rpm}$, se realiza un lavado con etanol al $70 \%$ y se resuspende con $50 \mathrm{ml}$ de TE y se almacena a $-20^{\circ} \mathrm{C}$; y 2). El método propuesto en este trabajo, que consistió en inocular $5 \mathrm{gr}$ de panículas maceradas, en medio LB (10 gr de Triptona, $5 \mathrm{gr}$ de Extracto de levadura y $10 \mathrm{gr}$ de $\mathrm{NaCl} / 1$ litro), y se dejaron en agitación a temperatura ambiente durante 24 horas. La calidad del ADN genómico se determinó mediante electroforesis en geles de agarosa al $1 \%$ y se cuantificó por espectrofotometría a 260 y $280 \mathrm{~nm}$. Posteriormente se tomaron $1.8 \mathrm{ml}$ del cultivo y se realizó el aislamiento del ADN utilizando el kit UltraClean® Microbial DNA Isolation de la casa comercial MoBio.

\section{Identificación molecular}

En la identificación molecular se emplearon los cebadores específicos RHGF GGGATTCATTTCCTTAGTAAC y RHGR GCGATTACTAGCGATTCCAGC (Gijon et al., 2011; Lipuma et al, 1999), que amplifican un fragmento de $511 \mathrm{pb}$ de una secuencia del gen ribosomal 16S del género Burkholderiaceae; y los cebadores glu-FW GAAGTGTCGCCGATGGAG y glu-REV CCTTCACCGACAGCACGCAT (Karki et al., 2012; Maeda, et al., 2006), que amplifican un fragmento de 529 pb del gen gyrB de B. glumae. Las muestras de ADN fueron amplificadas en un volumen final de $50 \mu$ conteniendo 1X buffer para PCR, 2.5 $\mathrm{mM} \mathrm{MgCl} 2,200 \mathrm{mM}$ dNTP, $1 \mathrm{U}$ de Taq polimerasa (Bioline), $1 \mu \mathrm{M}$ de cada cebador y $2 \mu \mathrm{l}$ de ADN. Las condiciones de la amplificación para Burkholderia sp consistieron en una desnaturalización inicial a $95^{\circ} \mathrm{C}$ por $5 \mathrm{~min}$, seguida de 30 ciclos de $94^{\circ} \mathrm{C}$ por $1 \mathrm{~min}, 55^{\circ} \mathrm{C}$ por $1 \mathrm{~min}$ y $72^{\circ} \mathrm{C}$ por $1 \mathrm{~min}$; y una extensión final a $72^{\circ} \mathrm{C}$ por 7 min.; y para $B$. glumae una desnaturalización inicial a $94^{\circ} \mathrm{C}$ por $5 \mathrm{~min}$, seguida de 35 ciclos de $94^{\circ} \mathrm{C}$ por $1 \mathrm{~min}, 58^{\circ} \mathrm{C}$ por $1 \mathrm{~min}$ y $72^{\circ} \mathrm{C}$ por $1 \mathrm{~min}$; y una extensión final a $72^{\circ} \mathrm{C}$ por $10 \mathrm{~min}$. Los productos de la PCR fueron visualizados en geles de agarosa al $1 \%$ y teñidos con bromuro de etidio.

\section{Caracterización molecular}

Los marcadores y cebadores utilizados fueron BOX-PCR (CTACGGCAAGGCGACGCTGACG) (Nayak et al. 2011) y MB1 (TGTACATAAGACGAAGCCC) (Galvis y Moreno, 2104; Brumlik et al. 2004). El volumen final de la mezcla de reacción fue de $50 \mu \mathrm{L}$, con $200 \mu \mathrm{M}$ de dNTPs, $2 \mathrm{U}$ de Taq Polimerasa, $5 \mathrm{mM}$ de $\mathrm{MgCl}_{2}, 1 \mu \mathrm{M}$ de cada cebador y $2 \mu \mathrm{l}$ del ADN aislado. La amplificación consistió en una desnaturalización inicial a $94{ }^{\circ} \mathrm{C}$ por 5 minutos, seguidos de 32 ciclos con una desnaturalización por 1 minuto a $94{ }^{\circ} \mathrm{C}$, hibridación por 1 minuto a $55^{\circ} \mathrm{C}$ para BOX-PCR y $45^{\circ} \mathrm{C}$ para MB1, y polimerización por 2 minutos a $72{ }^{\circ} \mathrm{C}$; y una extensión final de $72 \stackrel{\circ}{\circ} \mathrm{C}$ por 7 minutos. Los perfiles de bandas se separaron por electroforesis en geles de agarosa al $1,4 \%$ por 3 horas a $50 \mathrm{~V}$, y teñidos con bromuro de etidio. Para el análisis filogenético se seleccionaron todas las bandas claramente identificables y se elaboró una matriz de presencia y ausencia, para luego ser transformada con el software NTSYS 2.0 en una matriz de similaridad usando el coeficiente de Jaccard (Soll., 2000) seguido de una matriz de agrupamiento con el método de UPGMA (Unweighted Pair Group Arithmetic Mean).

\section{RESULTADOS}

\section{Aislamiento microbiológico}

Utilizando panículas de arroz con evidencia de pudrición, se obtuvieron 64 aislados (50 del municipio de Cúcuta, y 14 del municipio de El Zulia) en medio JMV, presentando características macroscópicas típicas de Burkholderia sp. y B. glumae: colonias grandes de color blanco, mucoides y con una pigmentación amarilla en su centro. 


\section{Identificación molecular}

En la validación de la identificación por PCR, los dos métodos empleados para el aislamiento del ADN a partir de panículas de arroz, mostraron amplificaciones esperadas para Burkholderia sp y B. glumae. Utilizando los cebadores RHGF y RHGR para la identificación de Burkholderia sp. (Gijon et al., 2011; Lipuma et al., 1999), se obtuvieron amplificaciones de 511 pb en 55 de las 64 muestras procesadas (86\% postivos para Burkholderia sp.) (Figura 1a); y en la identificación específica de B. glumae con los cebadores glu-FW y glu-REV (Karki et al., 2012; Maeda, et al., 2006), 41 de los 55 aislados, mostraron un producto de $529 \mathrm{pb}$ en la PCR, que corresponden a un $74 \%$ de muestras positivas (Figura1b). De los 50 aislados provenientes del municipio de Cúcuta, 27 fueron identificados como B. glumae por PCR (54\% positivos), y todos los aislados provenientes de El Zulia fueron identificados como B. glumae por PCR (100\% positivos). En la figura 1, las letras indican lo que sigue: a. Burkholderia sp. Línea MM: marcador de peso molecular Hyperladder II; Linea C-: Control negativo PCR; Linea Bc: B. cepacia; Linea Bg: B. glumae;Lineas 1 a 8: aislados a partir de plantas de arroz. Se observa una banda de 511 pb. b. B. glumae. Línea MM: marcador de peso molecular Hyperladder II; Lineas 1 a 8: aislados a partir de plantas de arroz; Linea Bg: B. glumae; Linea Bc: B. cepacia; Linea C-: Control negativo PCR. Se observa una banda de 529 pb.

\section{Caracterización molecular}

Se utilizaron los 41 aislados identificados como B. glumae mediante PCR, empleando los cebadores glu-FW y glu-REV (Karki et al., 2012; Maeda, et al., 2006). La caracterización molecular con los marcadores MB1 y BOX-PCR, generaron patrones de bandas definidas y reproducibles, y todos los aislados analizados fueron polimórficos, ya que no compartían el mismo perfil genético.
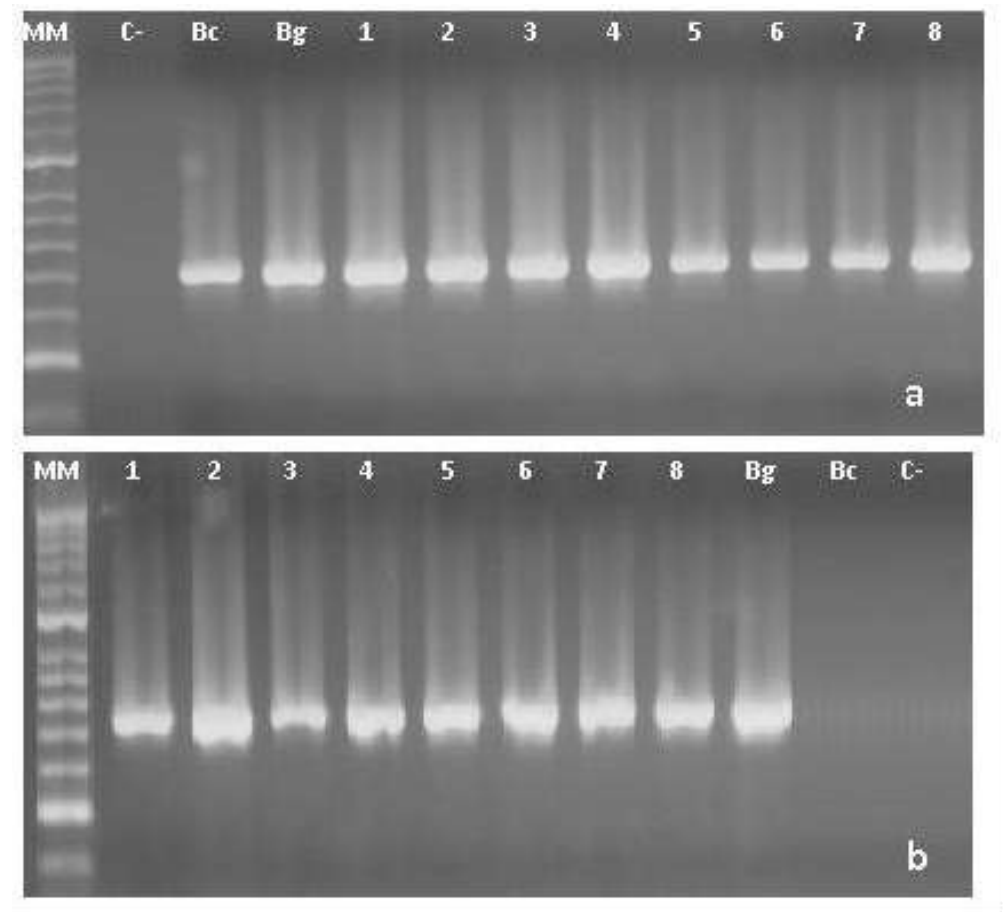

Fig. 1: Identificacion por PCR de Burkholderia sp y B. glumae.

Con el marcador MB1 las amplificaciones presentaron un número de bandas en los aislados y controles que varió entre 3 y 9 , con un tamaño aproximado de 2000 a 100 pb. Se observaron aislados que presentaban los mismos perfiles de bandas: BurG34 y BurG35 con 5 bandas compartidas; BurG15, BurG16 y BurG17 con 3 bandas; BurG25, BurG28, BurG29, BurG30, BurG31 y BurG32 con 4 bandas; y BurG19 y BurG22 que compartían 6 bandas. Los patrones observados en la amplificación con el marcador BOX-PCR presentaron un número de bandas que varió entre 4 y 15, con un tamaño aproximado de 2000 a 100 pb. Los aislados BurG40 y BurG41 compartían 8 bandas; BurG16 y BurG21 4 bandas; y BurG24 y BurG25 compartían 5 bandas.

\section{Análisis filogenético}

El análisis filogenético con el marcador MB1 mostró un índice de similaridad de 0.13 en todos los aislados de B. glumae, los cuales se agruparon en 4 clusters; el cluster I agrupa 10 aislados, donde BurG34 y BurG35 presentan un $100 \%$ de similitud; el cluster // agrupa 22 aislados con un $23 \%$ de similitud, y dentro de 
éste se forman 2 grupos; el primero incluye los aislados BurG15, BurG16 y BurG17 con 100\% de similitud y el segundo BurG25, BurG27, BurG28, BurG29, BurG30 y BurG31 también con 100\% de similitud; el cluster III con un 43\% de similitud agrupa los aislados BurG13 y BurG26; el cluster IV agrupa 7 aislados con un $20 \%$ de similitud, donde los aislados BurG19 y BurG22 se agrupan con $100 \%$ de similaridad (Figura $2 a$ ).

En el análisis filogenético con el marcador BOX-PCR se observó que el índice de similaridad de los aislados de $B$. glumae fue aproximadamente de 0.08, y se organizaron en 4 clusters; el cluster I agrupa 10 aislados, donde BurG40 y BurG41 presentan $100 \%$ de similitud; en el cluster // se encuentran 24 aislados con un $21 \%$ de similitud con respecto a los demás aislados en estudio; aquí los aislados BurG 16 y BurG21, y al igual que BurG24 y Burg25, comparten un 100\% de similaridad; el cluster III agrupa 7 aislados con un $20 \%$ de similaridad; y en el cluster IV el aislado BurG3 presentó una diferencia del $90 \%$ frente a los 40 aislados restantes utilizados en este estudio (Figura $2 \mathrm{~b}$ ).

En la figura 2 la simbología es como sigue: a. MB1. El índice de similaridad de los aislados de $B$. glumae fue de 13\%, generando 4 clusters; los aislados BurG34 y BurG35 se agruparon con un 100\% de similitud en el cluster l; y los grupos de aislados BurG15, BurG16 y BurG17, y BurG25, BurG27, BurG28, BurG29, BurG30, y BurG31 presentaron 100\%. de similitud en el cluster II. b. BOX-PCR. El análisis filogenético generó 4 clusters con un indice de similaridad de 0,8\%. En el cluster II se agrupan 24 aislados con un $21 \%$ de similitud, donde los aislados BurG16 y BurG21 comparten un 100\% de similaridad.

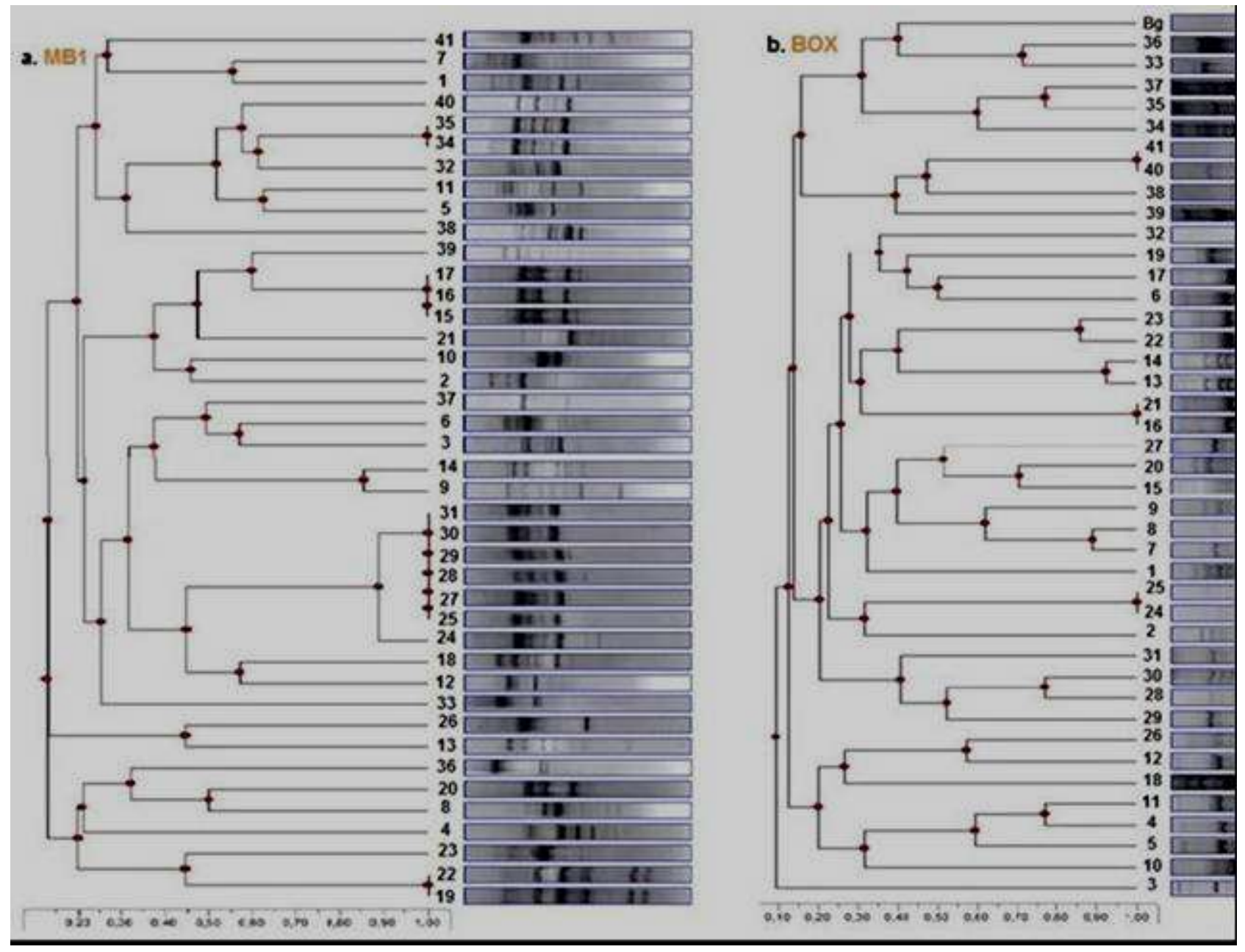

Fig. 2: Análisis filogenético

\section{DISCUSIÓN}

B. glumae invade las espiguillas, multiplicándose rápidamente y causando la pudrición bacteriana del grano o añublo de la panícula. Los síntomas aparecen desde la emergencia de la panícula, generando grandes pérdidas económicas a los productores (Gañan, 2011). El uso de medios selectivos y pruebas bioquímicas permiten la identificación solo hasta género y en ocasiones hasta especie; mientras que las técnicas moleculares permiten caracterizar e identificar especies, subespecies, serovariedades y cepas en una gran diversidad de microorganismos (Moreno y Galvis, 2013). Comparado con los métodos tradicionales de 
diagnóstico, la PCR convencional ofrece ventajas como su alta sensibilidad, la reproducibilidad, no se requiere cultivo puro antes de la detección, permite la identificación de patógenos en diversos huéspedes y tipos de muestras, y además es una técnica relativamente simple y rápida de realizar. La utilización de la PCR en laboratorios de diagnóstico para fines de rutina también está aumentando, especialmente para el cribado rápido de las muestras (Palacio-Bielsa et al., 2009). La PCR convencional y la PCR en tiempo real se han utilizado como los principales métodos para la identificación de varias especies de Burkholderia sp en muestras de suelo, de agua, de plantas infectadas y de células de mamíferos (Nandakumar et al., 2008). La PCR en tiempo real ofrece ventajas sobre la PCR convencional, debido a que los resultados son cuantitativos y están disponibles en tiempo real, además no se requiere mucho tiempo de procesamiento post-PCR (Sayler et al., 2006). A pesar de lo anterior, la PCR convencional no precisa de equipos sofisticados y los protocolos estandarizados para la identificación de microorganismos mediante esta técnica pueden adaptarse para ser realizados en la tecnología de PCR en tiempo real.

Palacio-Bielsa y colaboradores en el 2009, plantean que el bajo número inicial de copias de secuencias de ADN del patógeno, provocan que los primeros ciclos de amplificación sean críticos, dando lugar a falsos negativos; y también reportan que compuestos derivados de plantas actúan como inhibidores de la PCR. Para evitar la posibilidad de obtener falsos negativos, en este trabajo se implementó una metodología sencilla para la identificación específica de B. glumae en aislados y en panículas de plantas de arroz, utilizando los cebadores glu-FW y glu-REV que amplifican una secuencia del gen gyrB, mediante la siembra de panículas en medio LB para la obtención de cultivos bacterianos y su posterior aislamiento de ADN e identificación por PCR. Los métodos de enriquecimiento facilitan la detección de patógenos por medio del aumento de su número y la disminución de los inhibidores y han demostrado éxito en la identificación de bacterias en muestras de suelo, semillas y tejidos de plantas asintomáticas (Palacio-Bielsa et al., 2009).

Los resultados en la identificación por PCR mostraron un alto porcentaje de muestras positivas para $B$. glumae, lo que permite inferir que esta bacteria se encuentra establecida en los cultivos de los municipios de Cúcuta y El Zulia, Norte de Santander, Colombia. Una de las principales causas del aumento de $B$. glumae con los síntomas característicos de $\mathrm{ABP}$, es la variabilidad climática, donde condiciones de altas temperaturas nocturnas y humedades relativas altas, durante el desarrollo del cultivo, favorecen el crecimiento de B. glumae (Flórez y Uribe, 2011). Otras causas que favorecen el desarrollo de esta bacteria son el empleo de semillas contaminadas, un manejo agronómico inadecuado, una deficiente preparación del suelo y plantas con estrés fisiológico (Castillo et al., 2011).

El análisis de la caracterización molecular con los marcadores MB1 y BOX-PCR reveló variaciones en la estructura del genoma entre los aislados de B. glumae, evidenciando que existen diversos genotipos en las dos zonas analizadas, Cúcuta y El Zulia. Sin embargo estos marcadores permitieron el agrupamiento de los aislados de acuerdo a su distribución geográfica, observándose que los aislados provenientes del Zulia (BurG1, BurG3, BurG4, BurG5, BurG7, BurG8 y BurG9, BurG10, BurG11, BurG13 y BurG14) se organizaron en grupos, mostrando una relación entre ellos. Resultados similares fueron reportados por Bravo et al., (2010) quienes encontraron una alta variabilidad genética en los aislamientos recolectados en Colombia, observándose que los grupos obtenidos lograron correlacionar la procedencia geográfica de los mismos. Karki y colaboradores en el 2012, detectaron variaciones genéticas en aislados de $B$. glumae empleando los marcadores BOX-PCR y ERIC PCR, observando una relación de acuerdo a su procedencia geográfica y presencia de pigmentación. La gran variabilidad de $B$. glumae es demostrada en un estudio realizado por Francis y colaboradores en el 2013, quienes secuencian dos cepas de B. glumae, 336gr-1 y BGR1, revelando numerosas regiones únicas en cada uno de los genomas de las cepas analizadas. Fory y colaboradores en el 2014, realizan un análisis comparativo de los genomas de $B$. glumae y $B$. gladioli y observan que los factores de virulencia son altamente conservados entre las dos especies, pero también identificaron características genotípicas propias entre las dos cepas que podrían contribuir a las diferencias fenotípicas de la enfermedad. Otros estudios de caracterización molecular, realizados en bacterias diazotrofas, muestran gran diversidad genética, De Bruijn (1992) analiza los patrones de bandas generados por rep-PCR y ERIC-PCR en 15 cepas de Rhizobium meliloti, donde se observa un alto polimorfismo con perfiles únicos; Cottyn y colaboradores en el 2001, caracterizan 428 aislados de bacterias asociadas al arroz mediante BOX-PCR, obteniendo 151 tipos únicos de perfiles, que permitieron identificar los géneros predominantes: Enterobacter sp. (25\%), Bacillus sp. (22\%), y Pseudomonas sp. (14\%).

La variabilidad de $B$. glumae está relacionada con su respuesta ante diversos ambientes y condiciones requeridas para su patogenicidad. La diversidad genética presentada entre los aislados de este estudio, probablemente, se puede relacionar con su capacidad de patogenicidad, ya que estos se obtuvieron de panículas con evidencia de pudrición, demostrando que dentro de una misma zona geográfica pueden presentarse aislados con diferentes niveles de virulencia. La patogénesis de $B$. glumae es un proceso complejo que abarca múltiples factores de virulencia, para poder colonizar y multiplicarse en los tejidos vegetales, los cuales se consideran que son pobres en nutrientes, con bajos niveles de oxígeno y poca 
concentración de hierro. Estos factores de virulencia se rigen principalmente por un sistema global de percepción denominado Quórum-Sensing (QS) que corresponde a un proceso en el cual las bacterias se comunican con otras de su misma especie para coordinar su comportamiento y funcionar como un organismo multicelular y cuya expresión depende de la densidad de la población. El QS involucran mecanismos de señalización que desempeñan papeles importantes en la patogenicidad de $B$. glumae, como en la síntesis de transporte de la fitotoxina Toxoflavina, en la regulación transcripcional para la síntesis de flagelos polares y en la producción de enzimas extracelulares (Kim et al., 2014; Flórez \& Uribe, 2011)

La implementación de la técnica de identificación molecular mediante PCR podrá ser utilizada en los laboratorios de referencia y control fitosanitario de la región, para la determinación directa de este patógeno en plantas con o sin síntomas, convirtiéndose en una herramienta efectiva para el control de esta enfermedad. El análisis genético por marcadores moleculares permite agrupar o separar individuos de una misma especie, y poder relacionar estas características con la interacción planta-patógeno, la evaluación de alternativas de prevención y control de la enfermedad, o como prueba complementaria para la selección de variedades tolerantes a la enfermedad.

\section{CONCLUSIONES}

La estandarización en esta investigación del aislamiento del ADN a partir de panículas y de la PCR como técnica de diagnóstico molecular, permitirá detectar, de manera específica, la presencia de bacterias patógenas, como B. glumae, en diversas muestras de plantas de arroz provenientes de las zonas productoras de la región y del país, convirtiéndose en una herramienta efectiva para el control de esta enfermedad. Debido a la sensibilidad de la rep-PCR para la genotipificación exacta de microorganismos a nivel de especie o subespecie en estudios de comunidades microbianas, dinámicas poblacionales e interacciones huésped-microorganismos; se logró en este estudio conocer las relaciones filogenéticas entre los aislados de $B$. glumae, proporcionando información sobre la diversidad genética y su relación con el origen geográfico, para poder, posteriormente, conocer su posible vínculo con la virulencia de las cepas.

\section{REFERENCIAS}

Bravo, D. y otros cinco autores. Variabilidad Genética y Patogénica de la población de Burkholderia glumae en Colombia. XI Conf.a Internacional de Arroz para América Latina y el Caribe. Cali, Colombia (2010)

Brumlik, M. y otros seis autores. Genetic diversity among Bacillus anthracis, Bacillus cereus and Bacillus thuringiensis strains using repetitive element polymorphism-PCR. Pol J Microbiol: 53(4), 215-225. (2004)

Castillo, L. y otros siete autores. Cambio climático y producción de arroz. Revista Arroz: 58, 5-12. (2011)

Cottyn, B. y otros cinco autores. Bacterial populations associated with rice seed in the tropical environment. Phytopathology: 91(3):282-92. (2001)

Cristo, E., N. Pérez, M. Gonzales y R. Cárdenas. Evaluación de líneas de arroz obtenidas mediante cultivo in vitro de anteras para condiciones de bajos suministros de agua. Cultivos Tropicales: 31(3), 47-50. (2010)

Cuevas, A. El clima y el cultivo del arroz en Norte de Santander. Revista Arroz: 60(497), 4-8. (2012)

De Bruijin, F. Use of repetitive (repetitive extragenic palindromic and enterobacterial repetitive intergeneric consensus) sequences and the polymerase chain reaction to fingerprint the genomes of Rhizobium meliloti isolates and other soil bacteria. Applied and Environmental Microbiology: 58 (7), 2180-2187. (1992)

Diago, M. y otros nueve autores. Un buen manejo del cultivo, verdadera barrera contra el añublo bacterial. Revista Arroz: 57(482), 30-38. (2009)

Fedearroz Federación Nacional de Arroceros. Proyecto AMTEC: Adopción Masiva de Tecnología. Documento interno. (2012)

Flórez, N. y D. Uribe. Determinación de la infección de Burkholderia glumae en semillas de variedades comerciales colombianas de arroz. Rev. Facultad Nacional de Agronomía: 64(2), 6093-6104. (2011)

Fory, P. y otros seis autores. Comparative Analysis of Two Emerging Rice Seed Bacterial Pathogens. Phytopathology: 104(5), 436-444. (2014)

Francis, F. y otros cinco autores. Comparative genomic analysis of two Burkholderia glumae strains from different geographic origins reveals a high degree of plasticity in genome structure associated with genomic islands. Molecular Genetics and Genomics: 288, 195-203. (2013) 
Galvis, F. y L. Moreno. Caracterización molecular mediante rep-pcr de aislados nativos de Bacillus thuringiensis, obtenidos de muestras de suelo. Agronomía Costarricense: 38(1), 223-229. (2014)

Gañan, L. Manejo integrado del añublo bacterial de la panícula del arroz (Oryza sativa l.) causado por Burkholderia glumae Kurita \& Tabei: una revisión. Agronomía: 19(2), 79-90. (2011)

Gijon, A. y otros seis autores. Leaf stripe and stem rot caused by Burkholderia gladioli, a new maize disease in Mexico. Journal of Phytopathology: 159 (5), 377-381. (2011)

Ham, J., R. Melanson y M. Rush. Burkholderia glumae: next major pathogen of rice?. Molecular Plant Pathology: 12(4), 32-339. (2011)

Karki, H. y otros cuatro autores. Diversities in Virulence, Antifungal Activity, Pigmentation and DNA Fingerprint among Strains of Burkholderia glumae. PLoS ONE: 7(9), e45376. (2012)

Lipuma, J. y otros 6 autores. Development of rRNA-Based PCR Assays for Identification of Burkholderia cepacia Complex Isolates Recovered from Cystic Fibrosis Patients. Journal of Clinical Microbiology: 37(10), 3167-3170. (1999)

Lu, Y. y otros seis autores. Isolation and characterization of nucleotide-binding site and C-terminal leucinerich repeat-resistance gene candidates in bananas. Genet Mol Res: 10(4), 3098-108. (2011)

Lupski, J. y G. Weinstock. Short, interspersed repetitive DNA sequences in prokaryotic genomes. Journal of Bacteriology: 174(14), 4525-4529. (1992)

Kim, S, y otros seis autores. Understanding pathogenic Burkholderia glumae metabolic and signaling pathways within rice tissues through in vivo transcriptome analyses. Gene: 547(1), 77-85. (2014)

Maeda Y. Phylogenetic study and multiplex PCR-based detection of Burkholderia plantarii, Burkholderia glumae and Burkholderia gladioli using gyrB and rpoD sequences. Int J Syst Evol Microbiol: 56, 1031-1038. (2006)

Moreno, L. y F. Galvis. Potencial biofertilizante de bacterias diazótrofas aisladas de muestras de suelo rizosférico. Pastos y Forrajes: 36 (1), 33-37. (2013)

Nandakumar, R. y otros cuatro autores. Burkholderia glumae and B. gladioli Cause Bacterial Panicle Blight in Rice in the Southern United States. Plant Dis: 93(9), 896-905. (2009).

Nandakumar, R, y otros cuatro autores. Evidence for the soilborne nature of the rice sheath rot and panicle blight pathogen, Burkholderia gladioli. Canadian Journal of Plant Pathology: 30(1), 148-154. (2008)

Nayak, B., B. Badgley y V. Harwood. Comparison of genotypic and phylogenetic relationships of environmental Enterococcus isolates by BOX-PCR typing and $16 S$ rRNA gene sequencing. Appl Environ Microbiol: 77(14), 5050-5055. (2011)

Onasanya, A., y otros trece autores. Development of a Combined Molecular Diagnostic and DNA Fingerprinting Technique for Rice Bacteria Pathogens in Africa. Biotechnology: 9(2), 89-105. (2010)

Palacio-Bielsa, A., M. Cambra y M. López. PCR detection and identification of plant-pathogenic bacteria: updated review of protocols (1989-2007). Journal of Plant Pathology: 91(2), 249-297. (2009)

Pérez, A, J. Rojas y J. Fuentes. Diversidad de bacterias endófitas asociadas a raíces del pasto colosuana (Bothriochloa pertusa) en tres localidades del departamento de Sucre, Colombia. Acta biol. Colombiana: 15(2), 219-228. (2010)

Rademaker, J. y otros siete autores. Comparison of AFLP and rep--PCR genomic fingerprint with DNA-DNA homology studies: Xanthomonas as a model system. Int J Syst Evol Microbiol: 50, 665-677. (2000)

Sayler, R., R. Cartwright y Y. Yang. Genetic characterization and real-time PCR detection of Burkholderia glumae, a newly emerging bacterial pathogen of rice in the United States. Plant Dis: 90,603-610. (2006)

Soll, D. The ins and outs of DNA fingerprinting the infectious fungi clinical. Clin Microbiol Rev. April: 13(2), 332-370. (2000) 